\title{
Solid-Phase Microtiter Radioimmunoassay Blocking Test for Detection of Antibodies to Escherichia coli Heat-Labile Enterotoxin
}

\author{
HARRY B. GREENBERG, ${ }^{1 *}$ MYRON M. LEVINE, ${ }^{2}$ MICHAEL H. MERSON, ${ }^{3}$ R. BRADLEY SACK, ${ }^{3}$ \\ DAVID A. SACK, ${ }^{3}$ JOSE R. VALDESUSO, ${ }^{1}$ DAVID NALIN, ${ }^{2}$ DAVID HOOVER, ${ }^{2}$ ROBERT $M$. \\ CHANOCK, $^{1}$ AND ALBERT Z. KAPIKIAN ${ }^{1}$ \\ Laboratory of Infectious Diseases, National Institute of Allergy and Infectious Diseases, Bethesda, \\ Maryland 20014 ${ }^{1}$; University of Maryland School of Medicine, Department of Infectious Disease, Baltimore, \\ Maryland 21201 ${ }^{2}$; and Johns Hopkins Hospital, Baltimore, Maryland $21210^{3}$
}

Received for publication 18 October 1978

The development of a solid-phase microtiter radioimmunoassay blocking test to detect serum antibody to Escherichia coli heat-labile enterotoxin is described. The assay is easy to perform and quantitate, and it is sensitive and specific.

Enterotoxigenic strains of Escherichia coli have been shown to be an important cause of diarrheal disease in both humans and animals (11). Some enterotoxigenic strains of $E$. coli produce a heat-labile toxin (LT) that is immunologically and physiologically related to cholera toxin (15). LT isolated from various strains of $E$. coli appears to be immunologically similar or identical (12). Some natural or experimental infections with LT-producing strains of $E$. coli induce a significant serum neutralizing antibody response to this toxin $(3,14)$.

The reliability of humoral antitoxin response as an indicator of infection is not clear. Serological responses have been observed in from less than $10 \%$ to greater than $70 \%$ of diarrhea patients or volunteers from whom LT-producing organisms were isolated $(3,7,14)$. In these studies several different bioassay neutralization tests were used to assess the antibody response to $E$. coli $\mathrm{LT}$. Currently the adrenal cell neutralization test is the most commonly used system (3). This assay appears to be moderately sensitive and specific but has some of the drawbacks inherent in a bioassay system that utilizes tissue culture, including bacterial contamination and difficulty of standardization. Recently a passive immune hemolysis assay for antibody to LT was described (4). This test may be more amenable to routine serological use, but because the test is complement dependent it is not suitable for measurement of a local secretory immunoglobulin A (IgA) response. Also the passive immune hemolysis assay requires partially purified LT for erythrocyte sensitization.

We have recently described a solid-phase radioimmunoassay (RIA) for detection of $E$. coli LT (5). This assay was modified to develop an
RIA blocking test for detection of antibody to $E$. coli LT. The test is specific and at least as sensitive as existing assays. It is easy to standardize, quantitate, and automate. Since it is a binding type assay, it is capable of measuring all immunoglobulin classes.

\section{MATERIALS AND METHODS}

Clinical specimens: sera. Paired sera were obtained from adult volunteers experimentally infected with $E$. coli B7A (0148:H28). Acute- and convalescent-phase sera were obtained from adults with acute diarrhea in Bangladesh (M. Merson, B. Sack, S. Islam, S. Golam, N. Huda, G. Kibriya, A. Mahamood, Q. Rhamed, A. Quder, R. Yolken, M. Rahaman, and A. Kapikian, 13th Joint Conference on Cholera, Atlanta, Ga., 19-21 September 1977, Abstr. p. 18). Preinfection and convalescent sera from American Peace Corps workers in Kenya were also studied (10). For antibody prevalence studies, sera obtained around the time of admission from children without diarrhea seen at Junior Village and Children's Hospital (Washington, D.C.) from 1954 through 1969 were used. Sera obtained during a study of common colds among University of Maryland students between 1958 and 1964 were also utilized. Paired sera from volunteers experimentally infected with Norwalk agent or children naturally infected with human rotavirus were collected during previously described studies $(2,6)$.

Reagents. (i) $E$. coli toxin. Toxigenic $E$. coli 4083 was grown under standard conditions, filtered, and lyophilized (9). The crude lyophilized filtrate was reconstituted in phosphate-buffered saline with $0.1 \%$ sodium azide and $1 \%$ bovine serum albumin, at a concentration of $40 \mu \mathrm{g}$ of lyophilized filtrate per $\mathrm{ml}$, and used as the test antigen. This preparation had a $50 \%$ effective dose of $100 \mu \mathrm{g}$ in the rabbit ileal loop.

(ii) Antiserum. Burro antiserum to cholera toxin (kindly provided by John Robbins, Bureau of Biologics, Food and Drug Administration) (1) was used to precoat microtiter plates and as a source of purified 
IgG antiserum to cholera toxin. The IgG fraction of the burro antiserum was prepared by a combination of ammonium sulfate precipitation and diethylaminoethyl-cellulose chromatography, as previously described (8). IgG was labeled with ${ }^{125}$ I by a modification of the method of Hunter and Greenwood as previously described (8). A ratio of $200 \mu \mathrm{Ci}$ of carrier-free ${ }^{125} \mathrm{I}$ per $\mu \mathrm{g}$ of purified IgG was employed, and unreacted iodine was separated from radiolabeled protein by chromatography on Sephadex G-50.

Test for antibody. Antitoxin was measured by a modification of our previously described micro-RIA test for detection of E. coli LT (5). Polyvinyl microtiter plates (Cooke Engineering, Alexandria, Va.) were precoated with burro anti-cholera toxin serum (50 $\mu \mathrm{l}$ per well) diluted $1 / 2,000$ in phosphate-buffered saline. After incubation of the plates at room temperature for $12 \mathrm{~h}$, the wells were washed and filled with phosphatebuffered saline containing $1 \%$ bovine serum albumin and stored at $4^{\circ} \mathrm{C}$ until used. For testing, each well was inoculated with $25 \mu$ l of stock $E$. coli crude antigen (strain 408-3, $40 \mu \mathrm{g} / \mathrm{ml}$ ) and the plates were incubated for $12 \mathrm{~h}$ at room temperature. The plates were then washed, $40 \mu \mathrm{l}$ of serial twofold dilutions of sera to be tested for antibody or buffer were added to the wells, and the plates were incubated at room temperature overnight. A 10- $\mu$ l sample of radiolabeled burro anticholera toxin IgG $(200,000 \mathrm{cpm})$ was then added to each well, and the incubation was continued for $3 \mathrm{~h}$ at $37^{\circ} \mathrm{C}$. The plates were then washed and cut with scissors, and individual wells were placed in gamma counting tubes for assay. A $\mathbf{4 0 \%}$ or greater reduction in residual radioactivity bound to a well containing a test sample of serum compared to a saline control was taken as evidence of the presence of anti-E. coli LT. All specimens were run in duplicate. The RIAs were performed without knowledge of adrenal cell antibody data. A fourfold or greater rise in titer was considered significant. A rabbit anti-crude $E$. coli LT serum (provided by $R$. B. Sack) was used as a standard and assigned 295 antitoxin units per $\mathrm{ml}$. The antiserum was standardized using the Swiss Serum Institute cholera antiserum (13).

Adrenal cell neutralization test. Some sera tested by RIA were also tested by adrenal cell neutralization assay. This assay was done as previously described (3). A fourfold or greater rise in titer was considered significant.

\section{RESULTS}

Representative titrations of antibody blocking activity by pre- and postinfection sera from a volunteer experimentally infected with an LTproducing $E$. coli are seen in Fig. 1. The curves are sigmoidal with $40 \%$ inhibition falling on the linear segment of the curve.

A comparison of the efficiency of the RIA blocking and the adrenal cell neutralization tests for detecting serological responses in volunteers experimentally infected with toxigenic $E$. coli is seen in Table 1. Both the techniques were efficient at detecting rises in ill volunteers. Nine of 10 volunteers who became ill developed an RIA

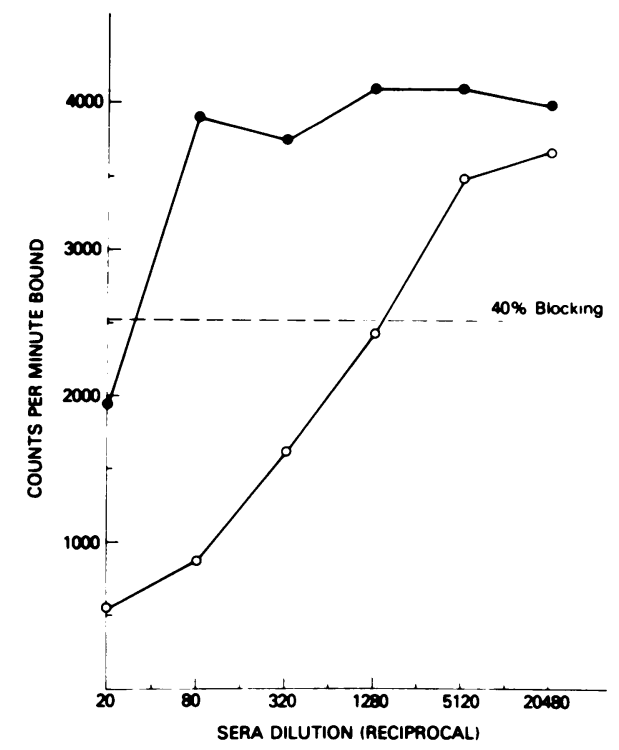

Fig. 1. Titration of sera from a volunteer infected with toxigenic $E$. coli by RIA blocking test. (O) Preinfection sera; $(O)$ postinfection sera. Blocking of bound ${ }^{125}$ I-labeled anticholera IgG of $40 \%$ or greater was taken as evidence of antitoxin activity.

blocking antibody response, and 7 had a serological response when tested by the adrenal cell method. Proportionately fewer non-ill volunteers responded when tested by either method. The adrenal cell assay detected one more seroresponse in the non-ill volunteers than did the RIA. RIA blocking antibody titers were between 5- and 10-fold higher than adrenal cell titers, and preexisting antibody was detected somewhat more commonly by the RIA blocking method.

We next compared the efficiency of the two techniques for detecting seroresponses using paired sera from adults with naturally occurring diarrhea in Kenya and Bangladesh. The results of the two tests were similar. Both methods detected significant rises in antibody in just under one-half of the patients shown to be shedding toxigenic $E$. coli (5 of 12; the same 5 individuals developed a response in both assays). Of 14 patients with acute diarrhea who did not have detectable toxigenic $E$. coli in their stools, 2 had a significant antitoxin rise by RIA blocking test and 1 of these also developed a rise by adrenal cell neutralization test. Again the actual antibody titer of these sera was considerably higher in the RIA blocking test than the adrenal cell neutralization assay; however, the relative correlation of the two tests was high (Fig. 2). No change in titer was detected with the RIA blocking test when four paired sera from volunteers infected with Norwalk agent or four paired sera 
TABLE 1. Comparison of adrenal cell neutralization and RIA blocking techniques for detecting antibody to $E$. coli $L T$ in volunteers experimentally infected with toxigenic E. coli

\begin{tabular}{|c|c|c|c|c|c|}
\hline \multirow[t]{2}{*}{ Volunteer no. } & \multirow{2}{*}{$\begin{array}{l}\text { Diarrheal ill- } \\
\text { ness }\end{array}$} & \multicolumn{2}{|c|}{ Actual RIA blocking titer $^{a}$ on day: } & \multicolumn{2}{|c|}{$\begin{array}{c}\text { Actual adrenal cell neutralization titer } \\
\text { on day: }\end{array}$} \\
\hline & & 0 & 12 & 0 & 12 \\
\hline $1^{c}$ & + & $\underline{40(6)}$ & $160(24)$ & $4(16)$ & $32(128)$ \\
\hline $2^{c}$ & + & $20(3)$ & $80(12)$ & $2(8)$ & $4(16)$ \\
\hline $3^{c}$ & + & $40(6)$ & $1,280(192)$ & $4(16)$ & $256(2,024)$ \\
\hline 4 & + & $40(6)$ & $160(24)$ & $16(64)$ & $\frac{200(2,024)}{32(128)}$ \\
\hline 5 & + & $20(3)$ & $160(24)$ & $<2(<8)$ & $8(32)$ \\
\hline 6 & + & $80(12)$ & $1,280(192)$ & $\frac{2(32)}{8(32)}$ & $64(256)$ \\
\hline 7 & + & $40(6)$ & $1,280(192)$ & $2(8)$ & $256(2,024)$ \\
\hline 8 & + & $20(3)$ & $640(96)$ & $2(8)$ & $\frac{200(2,024)}{16(64)}$ \\
\hline 9 & + & $80(12)$ & $\geq 1,280(\geq 192)$ & $2(8)$ & $256(2,024)$ \\
\hline 10 & - & $<20(<3)$ & $\frac{320(48)}{30}$ & $\frac{2(8)}{2(8)}$ & $\frac{200(2,024)}{32(128)}$ \\
\hline 11 & - & $320(48)$ & $\geq 1,280(\geq 192)$ & $8(32)$ & $128(512)$ \\
\hline 12 & - & $80(12)$ & $\frac{320(48)}{32)}$ & $8(32)$ & $\frac{120(128)}{32(128)}$ \\
\hline 13 & + & $20(3)$ & $\frac{0.0(60)}{40(6)}$ & $<2(<8)$ & $\frac{02(120)}{2(8)}$ \\
\hline $14^{\mathrm{c}}$ & - & $<20(<3)$ & $<20(<3)$ & $<2(<8)$ & $<2(<8)$ \\
\hline $15^{c}$ & - & $20(3)$ & $20(3)$ & $<2(<8)$ & $2(8)$ \\
\hline $16^{c}$ & - & $40(6)$ & $20(3)$ & $8(32)$ & $4(16)$ \\
\hline 17 & - & $40(6)$ & 80 (12) & $8(32)$ & $32(128)$ \\
\hline
\end{tabular}

${ }^{a}$ Rabbit anti-LT serum (supplied by R. B. Sack) was used as the standard and assigned a value of 295 antitoxin units per ml. Titer is expressed as reciprocal; parentheses indicate antitoxin level in units per milliliter. Significant rises are underlined.

${ }^{b}$ Swiss Serum Institute cholera antitoxin was used as the standard and assigned a value of 1,000 antitoxin units per $\mathrm{ml}$. Titer is expressed as reciprocal; parentheses indicate antitoxin level in units per milliliter. Significant rises are underlined.

${ }^{c}$ Volunteers received $10^{6}$ organisms. All others received $10^{8}$. All volunteers were culture positive for toxigenic E. coli after inoculation.

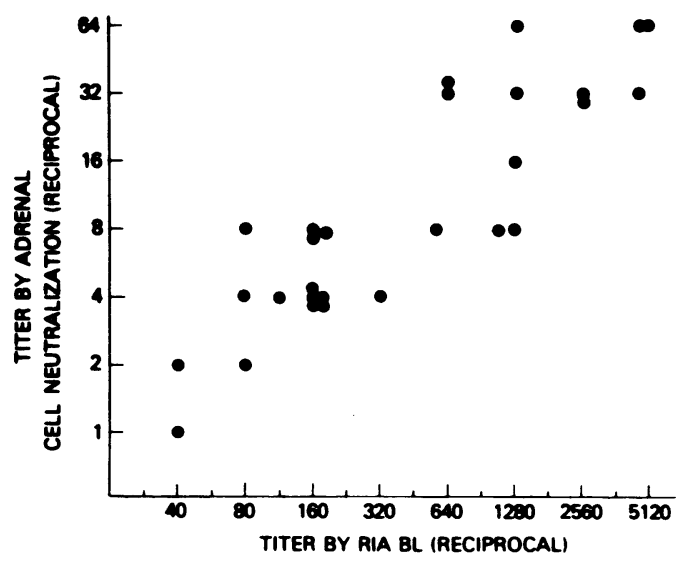

Fig. 2. Comparison of antitoxin titers of sera from adult Bengalis using the adrenal cell neutralization test and the RIA blocking (RIA BL) test. Sera represent acute and convalescent specimens obtained from patients with acute diarrhea. (Spearman rank correlation, $\rho=0.887, P<0.001$.)

from children with naturally acquired human rotavirus infection were tested.

The age prevalence of serum anti-LT was investigated by screening random sera obtained at Children's Hospital and Junior Village over the past 15 years. By 48 months of age, over $50 \%$ of the population studied had developed antibody to $E$. coli LT (Fig. 3). In studies not shown here it was found that over $70 \%$ of a group of University of Maryland students aged 17 through 26 had detectable serum anti-LT.

Because the RIA blocking technique appeared to readily detect anti-LT in pediatric sera, we studied the acute and convalescent bloods obtained from a group of children with acute diarrhea seen at Children's Hospital, Washington, D.C. (6). This group of patients (51) was a subset of a previously studied population (6). They were patients in whom, despite extensive investigation, human rotavirus could not be implicated as a cause of their diarrhea. None of these 51 individuals showed evidence of a serological response to $E$. coli LT.

\section{DISCUSSION}

Data presented here indicate that the RIA blocking test for anti-E. coli LT is both sensitive and specific. In experimental infection and natural disease the RIA blocking test was as efficient as the adrenal cell neutralization test for detecting seroresponses to LT. However, both techniques failed to detect a serological response in a significant number of naturally infected 


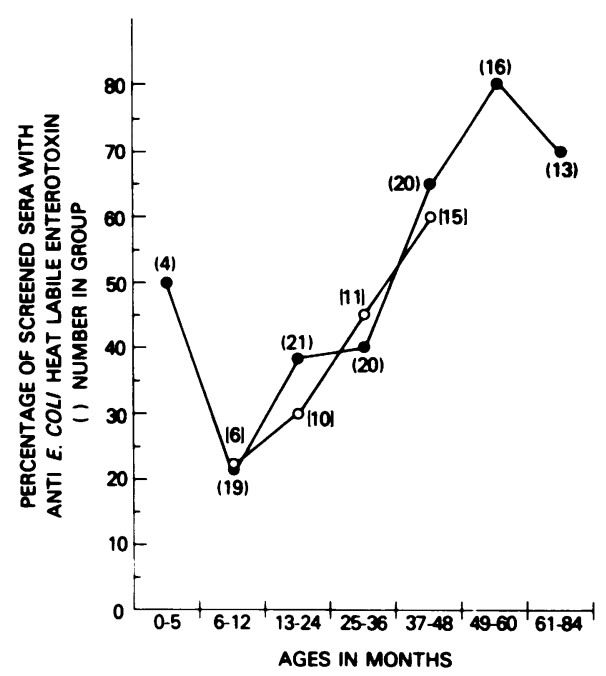

Fig. 3. Percentage of screened pediatric sera with anti-E. coli $L T$ as a function of age. Sera were screened at a dilution of 1/20. Specimens from (O) Children's Hospital; (O) Junior Village. Numbers in parentheses and brackets indicate total number of specimens tested. Rabbit anti-LT serum (provided by R. B. Sack) was used as a standard and assigned 295 antitoxin units per $\mathrm{ml}$. Positive sera have $\geq 1.5$ antitoxin units per $\mathrm{ml}$.

people who shed toxigenic $E$. coli. Since most of the people who failed to respond had detectable levels of preexisting antibody by both techniques, it seems unlikely that the inability to demonstrate a change in titer is due to a lack of sensitivity of the assays. Perhaps, at least in adults, serological responses are seen only after a relatively large antigenic stimulus (7).

The RIA blocking method appears to be somewhat more sensitive than the adrenal cell assay in that serum antibody titers are approximately 10 -fold higher in the RIA blocking assay. Also, some volunteer sera that were seronegative by the adrenal cell assay were found to have easily detectable antibody by the RIA blocking test. It is not clear whether this increased sensitivity might be useful in the serological analysis of pediatric sera or intestinal secretions where anti-LT seroconversions could occur below the level of detectability of the adrenal cell neutralization assay.

The seroepidemiologic data on anti-LT acquisition in the Washington, D.C. area are similar to findings among Apache Indian children in Arizona (13). In both cases, the data suggest that exposure to toxigenic $E$. coli is widespread and occurs early in life. Although it is conceivable that the rather high antibody prevalence seen here reflects some nonspecificity in the assay, this seems unlikely. First of all, antibody preva- lence was found to increase with age, as would be expected if it was due to a specific infectious etiology rather than a nonspecific cause. Second, antibody response in volunteer and field situations correlated to a high degree with the adrenal cell assay and with documented exposure to toxigenic $E$. coli.

Previous studies have shown that the human rotavirus is the major cause of severe infantile diarrhea in the winter months (6). There is, however, a significant proportion of infantile diarrhea for which an etiology is not apparent. We examined the paired sera from 51 individual children with rotavirus-negative diarrhea seen at Children's Hospital of Washington, D.C. (6). With the highly sensitive RIA blocking assay, no evidence for toxigenic $E$. coli infection was found. Our failure to detect anti-LT seroconversions in young urban children is probably due to the absence of significant toxigenic $E$. coli infection in this group. Alternatively, antitoxin titer rises after diarrheal disease associated with enterotoxigenic $E$. coli may not be regularly found in American children, no matter what assay system is used (13).

The RIA blocking test has several technical advantages over the adrenal cell neutralization assay. It is easy to standardize and quantitate. It is not dependent on observer judgment and is not subject to the vagaries of tissue culture. The assay can easily be modified to measure cholera toxin antiserum by substituting commercially available purified cholera toxin as the test antigen. In data not shown here, we found that the RIA blocking assay correlated to a high degree with several bioassays when a panel of coded anti-cholera toxin sera (kindly supplied by Carl Miller, National Institute of Allergy and Infections Disease) were tested. Preliminary studies indicate that the assay may be useful for investigating local immunity to LT. Intestinal secretions when run at low dilutions have previously proven difficult to work with in the adrenal cell assay because of their nonspecific toxic effect of cells. The problem of cytotoxicity is avoided with the RIA blocking assay.

\section{LTERATURE CITED}

1. Dafni, Z., and J. B. Robbins. 1976. Purification of heatlabile enterotoxin from Escherichia coli $078: \mathrm{H} 11$ by affinity chromatography with antisera to Vibrio cholerae toxin. J. Infect. Dis. 133:S138-S141.

2. Dolin, R., N. Blacklow, H. Dupont, S. Formal, R. Busche, J. Kasel, R. Chames, R. Hornick, and R. Chanock. 1971. Transmission of acute infectious nonbacterial gastroenteritis to volunteers by oral administration of stool filtrates. J. Infect. Dis. 123:307-312.

3. Donta, S. T., D. A. Sack, R. Wallace, H. Dupont, and R. B. Sack. 1974. Tissue culture assay for antibodies to heat-labile Escherichia coli enterotoxin. N. Engl. J. Med. 291:117-121. 
4. Evans, D. J., Jr., G. Ruiz-Palacios, D. G. Evans, H DuPont, L. K. Pickering, and J. Olarte. 1977. Humoral immune response to the heat-labile enterotoxin of Escherichia coli in naturally acquired diarrhea and antitoxin determination by passive immune hemolysis. Infect. Immun. 16:781-788.

5. Greenberg, H. B., D. A. Sack, W. Rodriguez, R. B Sack, R. G. Wyatt, A. R. Kalica, R. L. Horswood, R. M. Chanock, and A. Z. Kapikian. 1977. Microtiter solid-phase radioimmunoassay for detection of Esche. richia coli heat-labile enterotoxin. Infect. Immun. 17: 541-545.

6. Kapikian, A. Z., H. W. Kim, R. G. Wyatt, W. L. Cline, J. O. Arrobio, C. D. Brandt, W. J. Rodriguez, D. A. Sack, R. M. Chanock, and R. H. Parrot. 1976. Human reovirus-like agent as the major pathogen associated with "winter" gastroenteritis in hospitalized infants and young children. N. Engl. J. Med. 294:965-972.

7. Merson, M., G. Morris, D. Sack, J. Wells, J. Feeley, B. Sack, W. Creech, A. Z. Kapikian, and E. Gangarosa. 1976. Traveler's diarrhea in Mexico. A prospective study of physicians and family members attending a congress. N. Engl. J. Med. 294:1299-1305.

8. Purcell, R. H., D. C. Wong, H. J. Alter, and P. V. Holland. 1973. Microtiter solid-phase radioimmunoassay for hepatitis B antigen. Appl. Microbiol. 26:478-484.
9. Sack, B., J. Johnson, N. Pierce, D. Keren, and J. Yardley. 1976. Challenge of dogs with live entertoxigenic Escherichia coli and effects of repeated challenges on fluid secretions in jejunal thiry vella loops. J. Infect. Dis. 134:15-24.

10. Sack, D., D. Kamunsky, R. Sack, I. Wamola, F. Ørskov, I. Orskov, R. Slack, R. Arthur, and A. Z. Kapikian. 1977. Enterotoxigenic Escherichia coli diarrhea of travelers: a prospective study of American Peace Corps volunteers. Johns Hopkins Med. J. 141:63-70.

11. Sack, R. B. 1975. Human diarrheal disease caused by enterotoxigenic Escherichia coli. Annu. Rev. Microbiol. 29:333-353.

12. Sack, R. B., and J. Froehlich. 1977. Antigenic similarity of heat-labile enterotoxins of Escherichia coli. J. Clin. Microbiol. 5:570-572.

13. Sack, R. B., N. Hirschborn, W. E. Woodward, D. A. Sack, and R. A. Cash. 1975. Antibodies to heat-labile Escherichia coli enterotoxin in Apaches in Whiteriver, Arizona. Infect. Immun. 12:1475-1477.

14. Sack, R. B., B. Jacobs, and R. Mitra. 1974. Antitoxin responses to infections with enterotoxigenic Esche. richia coli. J. Infect. Dis. 129:330-335.

15. Smith, N. W., and R. B. Sack. 1973. Immunologic crossreactions of enterotoxins from Escherichia coli and Vibrio cholerae. J. Infect. Dis. 127:164-170. 